\title{
Analysis of Factors Affecting Alcohol and Tobacco Use by Bivariate Probit Model in Turkey
}

\section{Ömer Alkan ( $\square$ oalkan@atauni.edu.tr)}

Ataturk Universitesi https://orcid.org/0000-0002-3814-3539

\section{Hayri Abar}

Gaziantep Universitesi

\section{Özge Gençer}

Erzurum Teknik Universitesi

\section{Research article}

Keywords: alcohol drinking, smoking, statistical modeling, preventive medicine, socioeconomic factors, bivariate probit

Posted Date: May 6th, 2020

DOl: https://doi.org/10.21203/rs.3.rs-25747/v1

License: (c) (1) This work is licensed under a Creative Commons Attribution 4.0 International License. Read Full License 


\section{Abstract \\ Background}

Alcohol and tobacco use are interrelated risk factors. Risky alcohol and tobacco use are important public health problems with social and economic costs and is one of the leading causes of preventable death and disease. The aim of this study is to determine the factors of sociodemographic and economic on alcohol and tobacco use.

\section{Methods}

In this paper, a bivariate probit model was employed to determine the factors affecting alcohol and tobacco use among individuals the age of 15 and above living in Turkey. The data used in this paper was obtained from the Turkey Health Survey conducted in 2010, 2012, 2014, and 2016 by the Turkish Statistical Institute. Data were gathered from a total of 77,327 individuals.

\section{Results}

Results revealed that several key variables were found to be a significant determinant of alcohol and tobacco use, such as age, gender, educational status, marital status, monthly income, psychosocial support, and survey year.

\section{Conclusion}

In the last decade, a number of restrictions on combating alcohol and tobacco have been associated with reducing the alcohol and tobacco use habits of individuals. This is the first attempt that simultaneously compares both alcohol use and tobacco use using a Turkish sample.

\section{Introduction}

Alcohol and tobacco are legal psychoactive substances that are widely used in the world and have addictive properties [1].

Alcohol is the third most important risk factor for global disease and disability. Alcohol, which is a causal factor in 60 disease types and injuries, is also associated with more than 200 diseases. Approximately $4 \%$ of all deaths worldwide are due to the harmful use of alcohol. Alcohol-related deaths are higher in terms of numbers than the total of deaths due to HIV/AIDS, violence, and tuberculosis [2]. The abuse of alcohol has caused a number of health problems, traffic accidents, suicides as well as the commission of crime and the deterioration of family integrity and has become a major problem both psychosocially and economically because it has a negative impact on some areas of the economy and business life [3]. 
Tobacco use is an important risk factor and it is the cause of disease, early death, disability, and low quality of life to a significant extent [1]. World Health Organization Report states that more than 1.1 billion people used tobacco in 2015. According to the report, the number of men using tobacco (945 million) is much greater than the number of women (180 million). Despite the decrease in the prevalence of cigarette smoking worldwide, it is still observed that tobacco use is at high levels in many countries in the Eastern Mediterranean and African region according to the World Health Organization [4].

Alcohol and tobacco use are risky behaviors that are related to each other. The simultaneous use of alcohol and tobacco can also be correlated in two ways: The first is the internal connection (those who consume alcohol usually smoke, i.e., smokers consume alcohol). The second aspect is the situational linkage (these substances may be consumed together in similar circumstances). These phenomena may be explained by genetic, coping, pharmacological, learning, personality and cultural factors [5]. The negative effects of alcohol and tobacco use are higher in individuals who use both substances together. Twyman et al. stated in their study that the possibility of catching oral and larynx cancer is six times higher in the case of alcohol use, seven times higher in the case of tobacco use, and it is 38 times higher in the case of consuming alcohol and tobacco together [6]. Alcohol, especially when consumed in combination with cigarettes, provides a basis for the formation of mouth, pharynx, esophagus, and throat cancers at the rates of $25 \%$ and $80 \%$ [7]. The risk of illness and death from the use of both substances varies depending on the amount used chronically but affects almost all organs of the human body [1]. Alcohol and tobacco use have been proven to increase the risk of developing breast, colorectal, liver, pharynx, and head and neck cancers. Around the world, approximately 300 thousand mouth, 157 thousand throat and 142 thousand pharynx cancer cases are diagnosed each year [8]. Because a large number of alcohol addicts lose their lives because of diseases related to tobacco use, a synergic increase is seen in terms of cancer case rates (especially mouth and pharyngeal cancers), tobacco use has an aggravating impact on the possibility of alcohol addiction, and, while quitting either substance may have an impact on the use of the other substance, it is of utmost importance that the simultaneous use of alcohol and tobacco is handled in correlation [5].

Alcohol and tobacco use, which affects the mortality rates of societies, also paves the way for economic costs, poverty, disruption of family dynamics and lessening of efforts to raise healthy individuals. In addition, the negative impact of alcohol and tobacco use is an area that needs to be examined in detail because it affects society, the cultural structure in society, and the social structure that extends to the economic process [1].

It is important to identify and understand the determinants of the use of these substances when addressing the use of alcohol and tobacco. The aim of this study is to determine the factors of sociodemographic and economic on alcohol and tobacco use.

\section{Methods}


The data used in this study was obtained from the Turkey Health Survey conducted in 2010, 2012, 2014, and 2016 by the Turkish Statistical Institute. Turkey Health Survey is carried out on a regular basis every two years since 2008. All cities, towns, and villages within the borders of the Republic of Turkey were included in the populations for the sample selection. Cross-sectional data of individuals aged 15 years and over were employed in the study. Data were gathered from a total of 77,327 individuals (In 2010 14,281; in 2012 26,675; in 2014 19,129; in 2016 17,242).

\section{Measures And Variables}

The dependent variables of the study were the questions asking, "Do you smoke/use tobacco?" (yes; no); and "Do you use alcohol?" (yes; no) aimed to measure the use of tobacco and alcohol. The dependent variables in this study were categorical variables have two categories. Based on the established bivariate probit model, the categories of dependent variables are denoted as 1 if the individual uses tobacco, as 0 if the individual does not use tobacco, as 1 if the individual uses alcohol, and as 0 if the individual does not use alcohol.

The independent variables are ages (15-24, 25-34, 35-44, 45-54, 55-64, and 65 and above), gender (male/female), educational status (illiterate/illiterate and not completed school, elementary school, primary/secondary school or vocational secondary school, high school and equivalent schools, college, faculty, master's degree, doctorate degree), marital status (single, married, widowed/divorced), monthly income level (first income level, second income level, third income level, fourth income level, fifth income level), the status of receiving psychosocial support (no/yes), and the year in which the questionnaire was implemented $(2010,2012,2014,2016)$.

\section{Bivariate Probit Model}

In this study, a bivariate probit model was used to determine the factors affecting alcohol and tobacco use among individuals the age of 15 and above living in Turkey. There are two categorically dependent variables in the bivariate probit model. This is the case where two equations are associated with errors, each of which is produced by a probit equation [9]. This approach was proposed by Ashford and Sowden (1970) to model the system of binary results related to each other in the framework of regression [10].

\section{Results}

\section{Descriptive statistics}

The definitions of dependent and independent variables to be taken into consideration for the bivariate probit model are given in Table 1 . Table 1 shows that $12 \%$ of the respondents used alcohol and $28 \%$ used tobacco. In addition, $20 \%$ of the individuals subject to the research were in the $35-44$ age group, $45 \%$ were male, $36 \%$ were elementary school graduates, $69 \%$ were married, $26 \%$ were at the second income 
level, $3.9 \%$ received psychosocial support, and $34 \%$ of the participants were included in the survey in 2012. 
Table 1

Findings Related to Variables that can be Affective in Alcohol and Tobacco Use

Variables

Dependent variables

Tobacco Use

Unity if respondent tobacco use; zero otherwise

0,28

Alcohol Use

Unity if respondent alcohol use; zero otherwise

0,12
Mean Vif

Explanation

\section{Independent variables}

Age

\begin{tabular}{llll}
\hline $15-24$ & Unity if respond 15-24; zero otherwise & 0,18 & 4,22 \\
\hline $25-34$ & Unity if respond $25-34$; zero otherwise & 0,19 & 2,70 \\
\hline $35-44$ & Unity if respond 35-44; zero otherwise & 0,20 & 2,52 \\
\hline $45-54$ & Unity if respond 45-54; zero otherwise & 0,17 & 2,28 \\
\hline $55-64$ & Unity if respond 55-64; zero otherwise & 0,13 & 1,88 \\
\hline 65 and above & Unity if respond 65 and above; zero otherwise & 0,13 & (ref.) \\
\hline Gender & Unity if male; zero otherwise & 0,45 & 1,12
\end{tabular}

Educational status

Illiterate/Literate and not completed school

Unity if respond illiterate/literate and not completed school; zero otherwise

$0,16 \quad$ (ref.)

Elementary school

Unity if respond elementary school; zero

0,36

otherwise

Primary/secondary school or

Unity if respond primary/secondary school or

$0,18 \quad 2,44$

vocational secondary school

vocational secondary school; zero otherwise

High school and equivalent schools

Unity if respond high school and equivalent schools; zero otherwise

$0,17 \quad 2,32$

College, faculty, master's degree, doctorate degree

Unity if respond college, faculty, master's degree,

0,13

2,28 doctorate degree; zero otherwise

\section{Marital status}

Single

Married

Widowed/divorced
Unity if respond single; zero otherwise

Unity if respond married; zero otherwise

Unity if respond widowed/divorced; zero otherwise
$0,22 \quad$ (ref.)

$0,69 \quad 2,32$

$0,09 \quad 2,97$

Monthly income level 


\begin{tabular}{|lllc|}
\hline Variables & Explanation & Mean & Vif \\
\hline First income level (lowest) & $\begin{array}{l}\text { Unity if respond first income level (lowest); zero } \\
\text { otherwise }\end{array}$ & 0,25 & 2,52 \\
\hline Second income level & $\begin{array}{l}\text { Unity if respond second income level; zero } \\
\text { otherwise }\end{array}$ & 0,26 & 2,33 \\
\hline Third income level & $\begin{array}{l}\text { Unity if respond third income level; zero } \\
\text { otherwise }\end{array}$ & 0,20 & 2,01 \\
\hline Fourth income level & $\begin{array}{l}\text { Unity if respond fourth income level; zero } \\
\text { otherwise }\end{array}$ & 0,14 & 1,71 \\
\hline Fifth income level (highest) & $\begin{array}{l}\text { Unity if respond fifth income level (highest); zero } \\
\text { otherwise }\end{array}$ & 0,16 & (ref.) \\
\hline $\begin{array}{l}\text { The status of receiving } \\
\text { psychosocial support }\end{array}$ & $\begin{array}{l}\text { Unity if respondent psychosocial support } \\
\text { receives; zero otherwise }\end{array}$ & 0,04 & 1,01 \\
\hline Survey year & Unity if survey conduct in 2010; zero otherwise & 0,18 & (ref.) \\
\hline 2010 & Unity if survey conduct in 2012; zero otherwise & 0,34 & 1,96 \\
\hline 2012 & Unity if survey conduct in 2014; zero otherwise & 0,25 & 1,78 \\
\hline 2014 & Unity if survey conduct in 2016; zero otherwise & 0,22 & 1,76 \\
\hline 2016 & & & \\
\hline
\end{tabular}

Before the model estimation, in order to determine the problem of multiple linear correlation between the dependent variables, the VIF (Variance Inflation Factors) values were examined, and the results are shown in Table 1. The variables with VIF value 5 and above cause a moderate and those with 10 or above cause a high degree of multiple linear correlation problems [11]. As seen in Table 1, no independent variables taken into the model have five or more variance inflation factors. Accordingly, there are no dependent variables that cause multiple linear correlation problems between the variables in the model.

\subsection{Bivariate model estimation}

In the study, the bivariate probit model was used as qualitative variable econometric model because the dependent variables "tobacco use" and "alcohol use" are thought to be related to the nature of the data. Ordinal and nominal variables are defined as dummy variables in order to see the effects of the categories of all variables to be used to determine the factors that are effective for alcohol and tobacco use [11]. SPSS (Statistical Packages for the Social Sciences) and STATA (Data Analysis and Statistical Software) programs were used to analyze the data.

Analysis results of Bivariate probit model are given in Table 2. The likelihood ratio test for the significance of rho coefficient which shows the correlation of the residuals for the equations established for both dependent variables shows errors are correlated. That is, both equations must be estimated simultaneously and bivariate model should be used. The fact that rho is positive and significant indicates 
that there is a positive relationship between alcohol and tobacco use $(\mathrm{RHO}=0.420)$. Also the established model was statistically significant as a whole. 
Table 2

Bivariate Probit Model Estimation on Alcohol and Tobacco Use

\begin{tabular}{llllll} 
Variables & \multicolumn{3}{l}{ Tobacco use } & \multicolumn{3}{c}{ Alcohol use } \\
\cline { 2 - 6 } & $\boldsymbol{\beta}$ & $\begin{array}{l}\text { Std. } \\
\text { Error }\end{array}$ & $t$ & $\beta$ & $\begin{array}{l}\text { Std. } t \\
\text { Error }\end{array}$
\end{tabular}

Age (reference: 65 and above)

$\begin{array}{lllllll}15-24 & 0,564^{\mathrm{a}} & 0,052 & 10,81 & 0,145^{\mathrm{b}} & 0,063 & 2,31 \\ 25-34 & 1,086^{\mathrm{a}} & 0,041 & 26,44 & 0,503^{\mathrm{a}} & 0,052 & 9,67 \\ 35-44 & 1,064^{\mathrm{a}} & 0,039 & 27,07 & 0,558^{\mathrm{a}} & 0,050 & 11,16 \\ 45-54 & 0,925^{\mathrm{a}} & 0,039 & 23,53 & 0,505^{\mathrm{a}} & 0,050 & 10,10 \\ 55-64 & 0,592^{\mathrm{a}} & 0,040 & 14,72 & 0,442^{\mathrm{a}} & 0,051 & 8,61\end{array}$

Gender (reference: female)

Male

$0,865^{\mathrm{a}} \quad 0,019 \quad 46,07$

$0,842^{\mathrm{a}} \quad 0,023 \quad 37,21$

Educational status (reference: illiterate/literate and not completed school)

\begin{tabular}{|c|c|c|c|c|c|c|}
\hline Elementary school & $0,147^{a}$ & 0,033 & 4,43 & $0,716^{a}$ & 0,061 & 11,74 \\
\hline $\begin{array}{l}\text { Primary/secondary school or } \\
\text { vocational secondary school }\end{array}$ & $0,196^{\mathrm{a}}$ & 0,040 & 4,88 & $0,847^{a}$ & 0,066 & 12,93 \\
\hline High school and equivalent schools & $0,250^{\mathrm{a}}$ & 0,039 & 6,45 & $1,074^{\mathrm{a}}$ & 0,064 & 16,74 \\
\hline $\begin{array}{l}\text { College, faculty, master's degree, } \\
\text { doctorate degree }\end{array}$ & 0,015 & 0,042 & 0,36 & $1,203^{\mathrm{a}}$ & 0,066 & 18,30 \\
\hline \multicolumn{7}{|l|}{ Marital status (reference: single) } \\
\hline Married & $0,103^{a}$ & 0,032 & 3,19 & $-0,217^{a}$ & 0,037 & $-5,86$ \\
\hline Widowed/divorced & $0,467^{a}$ & 0,048 & 9,67 & $0,323^{a}$ & 0,056 & 5,80 \\
\hline
\end{tabular}

Monthly income level (reference: fifth income level)

\begin{tabular}{lllllll} 
First income level & 0,050 & 0,031 & 1,61 & $-0,388^{\mathrm{a}}$ & 0,036 & $-10,77$ \\
\hline Second income level & 0,028 & 0,031 & 0,92 & $-0,325^{\mathrm{a}}$ & 0,034 & $-9,53$ \\
\hline Third income level & 0,021 & 0,032 & 0,66 & $-0,245^{\mathrm{a}}$ & 0,035 & $-7,05$ \\
\hline Fourth income level & $0,070^{\mathrm{b}}$ & 0,031 & 2,29 & $-0,169^{\mathrm{a}}$ & 0,033 & $-5,08$
\end{tabular}

The status of receiving psychosocial support (reference: no) 


\begin{tabular}{|c|c|c|c|c|c|c|}
\hline \multirow[t]{2}{*}{ Variables } & \multicolumn{3}{|c|}{ Tobacco use } & \multicolumn{3}{|c|}{ Alcohol use } \\
\hline & $\beta$ & $\begin{array}{l}\text { Std. } \\
\text { Error }\end{array}$ & $t$ & $\beta$ & $\begin{array}{l}\text { Std. } \\
\text { Error }\end{array}$ & $\mathbf{t}$ \\
\hline Yes & $0,292^{a}$ & 0,045 & 6,54 & $0,190^{a}$ & 0,054 & 3,52 \\
\hline \multicolumn{7}{|c|}{ Survey year (reference: 2010) } \\
\hline 2012 & $-0,090^{a}$ & 0,017 & $-5,26$ & $-0,185^{a}$ & 0,021 & $-8,64$ \\
\hline 2014 & $0,096^{a}$ & 0,018 & 5,28 & $0,053^{b}$ & 0,022 & 2,36 \\
\hline 2016 & $0,072^{a}$ & 0,019 & 3,74 & $-0,079^{a}$ & 0,024 & $-3,32$ \\
\hline Constant & $-2,118^{a}$ & 0,059 & $-35,80$ & $-2,536^{a}$ & 0,083 & $-30,58$ \\
\hline $\mathrm{RHO}$ & $0,420^{a}$ & 0,014 & 29,04 & & & \\
\hline \multicolumn{7}{|c|}{ Likelihood-ratio test of rho $=0: \chi 2(1)=2622.1 \mathrm{P}>\chi 2=0,000(\mathrm{~N}=77322)$} \\
\hline${ }^{a} p<0.01 ;{ }^{b}<<0.05$ & & & & & & \\
\hline
\end{tabular}

The marginal effects of the dependent variables after parameter estimations are given in Table 3 . It is seen that probability of individuals use both alcohol and tobacco in the 15-24, 25-34, 35-44, 45-54, and 55-64 age groups are more than the reference group at the following percentages, $4.3 \%, 10.5 \%$, $10.9 \%, 9.7 \%$, and $7.4 \%$, respectively. The probability of men using both alcohol and tobacco is $12.7 \%$ higher than that of women. 
Table 3

Marginal Effects on Alcohol and Tobacco Use

\section{Variables}

$\begin{array}{|llll|}\begin{array}{l}\text { Both tobacco } \\ \text { and alcohol } \\ \text { use }\end{array} & \begin{array}{l}\text { Tobacco use } \\ \text { but not } \\ \text { alcohol }\end{array} & \begin{array}{l}\text { Non-tobacco } \\ \text { but alcohol } \\ \text { use }\end{array} & \begin{array}{l}\text { Both non- } \\ \text { tobacco and not } \\ \text { alcohol }\end{array} \\ \begin{array}{l}\mathrm{P}\left(\mathrm{Y}_{1}=1 / \mathrm{Y}_{2}\right. \\ =1)\end{array} & \begin{array}{l}\mathrm{P}\left(\mathrm{Y}_{1}=1 / \mathrm{Y}_{2}\right. \\ =0)\end{array} & \begin{array}{l}\mathrm{P}\left(\mathrm{Y}_{1}=0 / \mathrm{Y}_{2}\right. \\ =1)\end{array} & \mathrm{P}\left(\mathrm{Y}_{1}=0 / \mathrm{Y}_{2}=0\right) \\ \left(\mathrm{p}_{11}\right) & \left(\mathrm{p}_{10}\right) & \left(\mathrm{p}_{01}\right) & \left(\mathrm{p}_{00}\right)\end{array}$

Age (reference: 65 and above)

$15-24$

$25-34$

$35-44$

$45-54$

$55-64$

$0.043^{\mathrm{a}}$

$0.105^{\mathrm{a}}$

$0.109^{a}$

$0.097^{a}$

$0.074^{a}$

$0.132^{\mathrm{a}}$

$-0.016^{a}$

$-0.158^{a}$

Gender (reference: female)

Male

$0.127^{a}$

$0.141^{\mathrm{a}}$

$0.027^{\mathrm{a}}$

$(-) .295^{a}$

Educational status (reference: illiterate/literate and not completed school)

Elementary school

Primary/secondary school or vocational secondary school

High school and equivalent schools

College, faculty, master's degree, doctorate degree

Marital status (reference: single) $0.078^{\mathrm{a}}$

$0.094^{\mathrm{a}}$

$0.119^{a}$

$0.120^{a}$

$-0.033^{\mathrm{a}}$

$0.053^{\mathrm{a}}$

$-0.033^{a}$

$0.062^{\mathrm{a}}$

$-0.041^{a}$

$0.078^{a}$

$-0.115^{a}$

$0.101^{a}$

$-0.106^{a}$

$-0.099^{a}$

Married

$-0.016^{a}$

$0.048^{\mathrm{a}}$

$-0.024^{a}$

$-0.008$

Widowed/divorced

$0.056^{a}$

$0.089^{a}$

0.004

$-0.148^{\mathrm{a}}$

Monthly income level (reference: fifth income level)

\begin{tabular}{lllll} 
First income level & $-0.036^{\mathrm{a}}$ & $0.051^{\mathrm{a}}$ & $-0.035^{\mathrm{a}}$ & $0.020^{\mathrm{b}}$ \\
\hline Second income level & $-0.031^{\mathrm{a}}$ & $0.040^{\mathrm{a}}$ & $-0.029^{\mathrm{a}}$ & $0.020^{\mathrm{b}}$
\end{tabular}

${ }^{a} p<0.01 ;{ }^{b} p<0.05$ 


\begin{tabular}{|c|c|c|c|c|}
\hline \multirow[t]{3}{*}{ Variables } & $\begin{array}{l}\text { Both tobacco } \\
\text { and alcohol } \\
\text { use }\end{array}$ & $\begin{array}{l}\text { Tobacco use } \\
\text { but not } \\
\text { alcohol }\end{array}$ & $\begin{array}{l}\text { Non-tobacco } \\
\text { but alcohol } \\
\text { use }\end{array}$ & $\begin{array}{l}\text { Both non- } \\
\text { tobacco and not } \\
\text { alcohol }\end{array}$ \\
\hline & $\begin{array}{l}P\left(Y_{1}=1 / Y_{2}\right. \\
=1)\end{array}$ & $\begin{array}{l}P\left(Y_{1}=1 / Y_{2}\right. \\
=0)\end{array}$ & $\begin{array}{l}P\left(Y_{1}=0 / Y_{2}\right. \\
=1)\end{array}$ & $P\left(Y_{1}=0 / Y_{2}=0\right)$ \\
\hline & $\left(p_{11}\right)$ & $\left(p_{10}\right)$ & $\left(p_{01}\right)$ & $\left(p_{00}\right)$ \\
\hline Third income level & $-0.023^{a}$ & $0.030^{\mathrm{a}}$ & $-0.022^{\mathrm{a}}$ & 0.015 \\
\hline Fourth income level & $-0.013^{a}$ & $0.035^{\mathrm{a}}$ & $-0.018^{a}$ & -0.004 \\
\hline \multicolumn{5}{|c|}{ The status of receiving psychosocial support (reference: no) } \\
\hline Yes & 0.034 & $0.057^{\mathrm{a}}$ & 0.001 & $(-) .092^{\mathrm{a}}$ \\
\hline \multicolumn{5}{|c|}{ Survey year (reference: 2010) } \\
\hline 2012 & $-0.023^{a}$ & -0.005 & $-0.011^{a}$ & $0.039^{a}$ \\
\hline 2014 & $0.010^{\mathrm{a}}$ & $0.020^{\mathrm{a}}$ & -0.000 & $-0.029^{a}$ \\
\hline 2016 & -0.004 & 0.026 & $-0.010^{a}$ & $-0.012^{b}$ \\
\hline${ }^{a} p<0.01 ;{ }^{b} p<0.05$ & & & & \\
\hline
\end{tabular}

When the educational status was examined, it was determined that the individuals who were elementary school, secondary school, high school and university graduates have a $7.8 \%, 9.4 \%, 11.9 \%$ and $12 \%$ higher probability, respectively, of using alcohol and tobacco than the reference group.

The marital status of individuals also affects alcohol and tobacco use. The probability of using alcohol and tobacco among married individuals was found to be $1.6 \%$ less than from singles. The probability of using alcohol and tobacco among widowed/divorced individuals was found to be $5.6 \%$ higher from singles.

There are also remarkable conclusions about monthly income. Individuals within the first, second, third, and fourth level were found to be $3.6 \%, 3.4 \%, 2.3 \%$ and $1.3 \%$ less likely to use both alcohol and tobacco, respectively, than those with the highest income.

The variable of the year in which the questionnaire was conducted was also significant in the use of alcohol and tobacco. Individuals surveyed in 2012 were $2.3 \%$ less likely to use both alcohol and tobacco than in 2010. Individuals surveyed in 2016 are $0.4 \%$ less likely to use both alcohol and tobacco than in 2010. However, in 2014 , it was found that the individuals who were surveyed were $1 \%$ more likely to use both alcohol and tobacco than in 2010.

\section{Discussion}


Alcohol and tobacco use are risky behaviours related to each other. The use of these substances creates some negative health, social, and economic consequences not only for the individual but also for the whole society. These negative results are even more common among individuals who use both substances together. It is of utmost importance to identify and understand the determinants of abuse of these substances in order to minimize the negative effects of alcohol and tobacco use and to mitigate their impact on the individual and society [12].

In this study, impacts of sociodemographic factors on alcohol and tobacco use were determined. The cross-sectional data set in the research was obtained from Turkey Health Survey Questionnaire conducted in 2010, 2012, 2014, and 2016 by the Turkish Statistical Institute.

In most of the academic studies conducted with adults, it was seen that there is a significant relationship between age and alcohol and tobacco use [13-15]. In this study, it was found that all age categories were important determinants of alcohol and tobacco use, and the probability of both alcohol and tobacco use increased until a certain age and followed a decreasing with increasing age.

The effect of the gender on alcohol and tobacco use was another issue in the literature. This study showed that alcohol and tobacco use habits differed significantly in terms of gender, and it was concluded that men use more alcohol and tobacco than women. This result supports the literature [1619] In addition, alcohol and tobacco use in some societies is considered as inappropriate behaviors because of social, environmental, and cultural pressure, and social disapproval is considered to be one of the inevitable reasons for the low rate of using such substances in women. In traditional societies, in particular, the use of alcohol and tobacco is considered to be contrary to the characteristics related and ascribed to women. However, while men tend to be more prone to substance abuse in coping with their problems, women are less prone to substance use as women are more likely to seek help from their parents, friends, or professionals when faced with these problems. Moreover, alcohol and tobacco use are perceived as part of the male gender role in the areas affected by traditional values and serve to establish and maintain interpersonal and social ties [20]. As the frequent use of both alcohol and tobacco is known to be highly addictive and associated with adverse health outcomes, there is a need for integrated approaches that prevent alcohol and tobacco from being used together, especially in male individuals [17].

It was found that all categories of educational status were significant for alcohol and tobacco use. Education has an increasing effect on the use of alcohol and tobacco, it was observed that, as the education level increased, alcohol and tobacco use incrases. It is possible to find studies in parallel with this result in the literature [21]. However, the increase in the level of education increases the level of knowledge and awareness about the harms of alcohol and tobacco use, and this may have a diminishing effect on the simultaneous use of these substances. Different results were obtained from the results of this study $[15,22,23]$ because they reached the conclusion that when the level of education increases, high risk alcohol and tobacco consumption rate decreases. 
It was found that all categories of monthly income variable were negative and significant for alcohol and tobacco use. Those with low income levels (first, second, third, and fourth income levels) are less likely to use both alcohol and tobacco than those in the fifth income level. This may be related to the fact that individuals with higher income levels have easier access to such items than those with low income levels. Different results were obtained from the results of the study where they have demonstrated that alcohol and tobacco use decreased as income level increased $[6,22,24]$. According to the marital status of the individual, lifestyle may be the determinant of alcohol and tobacco use. In this study, the use of both substances was examined to determine whether such use was more likely with the individual who is living alone and is suffering from psychological stress and depression so the individual's marital status and seeking psychosocial support was examined in order to see whether these factors had an impact on the use of substances. The results show that individuals whose spouses have died or individuals who are separated from their spouses are more likely to use alcohol and tobacco than those who never got married. Similar results obtained from different studies show that individuals living alone or widowed/separated individuals are more inclined to use the said substances [6, 23]. Some studies suggested that the mortality rate of married individuals is lower than those who never got married and stated that married individuals are healthier and happier so marriage itself is a factor and presents a lifestyle which may prevent alcohol and tobacco (cigarette) addiction. The result obtained in the study suggested that married individuals have lower alcohol and tobacco use than those who never got married [25]. In 2012 and 2016, it was determined that the probability of using both alcohol and tobacco decreased compared to 2010. In the last decade, a number of restrictions with the purpose of combating alcohol and tobacco use have been associated with reducing the alcohol and tobacco use habits of individuals. It is clear that there is a need for further efforts in this context in order not to face serious health, social, and economic costs in the future.

\section{Conclusion}

Empirical findings suggest that alcohol and tobacco use are simultaneously linked to each other. In addition, gender (male), educational status (elementary school graduate, primary/secondary school or vocational secondary school, high school and equivalent schools, college, faculty, master, doctorate), age (15-24, 25-34, 35-44, 45-54) marital status (widowed/divorced) variables are important determinants of alcohol and tobacco use. In the prevention of alcohol and tobacco use, male individuals; college, faculty, graduate, doctorate, high school and equivalent school graduates and primary/secondary or vocational secondary school and elementary school graduates; individuals aged between 15-54 years; and widowed and divorced individuals are within the group to which more attention should be given with due diligence. Based on these results, public sports training programs, smoke-free areas, and other similar measures should be implemented to discourage the use of alcohol and tobacco and to reduce the rate of use of these substances.

This study draws attention to a better understanding and exploration of the relationships between addictive alcohol and tobacco use habits to support prevention policies. The study actually may allow 
policymakers or decision-makers to develop a common intervention plan to reduce the use of substance use by addressing both behaviors in order to achieve long-term healthy living and economic gains.

\section{Abbreviations}

Ref.:Reference category; VIF:Variance Inflation Factor; WHO:World Health Organization

\section{Declarations}

\section{Availability of data and materials}

The authors are pleased to share the dataset upon receiving request.

\section{Ethics approval and consent to participate}

This study has accomplished by using data of Turkey Health Survey conducted by Turkey Statistical Institute. Therefore, ethical approval was not required for this study.

\section{Consent for publication}

Not applicable.

\section{Competing interests}

The authors declare that they have no competing interests.

\section{Funding}

This research did not receive any specific grant from funding agencies in the public, commercial, or notfor-profit sectors

\section{Authors' contributions}

ÖA conceived and led the design and development of the study proposal. ÖA and HA supervised data collection, led the data analysis and drafting the manuscript. ÖG made substantial contributions to the conceptualization and design of the study, data interpretations and writing the manuscript. All authors read and approved the final version of the manuscript. 


\section{Acknowledgements}

The authors would like to thank the Turkish Statistical Institute for the data. The views and opinions expressed in this manuscript are those of the authors only and do not necessarily represent the views, official policy, or position of the Turkish Statistical Institute.

\section{References}

1. Varona P, Chang M, García RG, Bonet M. Tobacco and alcohol use in Cuban women. MEDICC Review. 2011;13(4):38-44.

2. Pathak NK, Kumar P. Alcohol and tobacco use among male aged 15 year and above in urban area of Ghaziabad city, Uttar Pradesh, India: an epidemiological study. International Journal Of Community Medicine Public Health. 2016;3(11):3026-9.

3. Ekuklu G, Deveci S, Eskiocak M, Berberoglu U, Saltik A. Alcoholism prevalence and some related factors in Edirne, Turkey. Yonsei Med J. 2004;45(2):207-14.

4. WHO. World health statistics 2016: monitoring health for the SDGs sustainable development goals: World Health Organization; 2016.

5. De Leon J, Rendon DM, Baca-Garcia E, Aizpuru F, Gonzalez-Pinto A, Anitua C, Diaz FJ. Association between smoking and alcohol use in the general population: stable and unstable odds ratios across two years in two different countries. Alcohol Alcohol. 2007;42(3):252-7.

6. Twyman L, Bonevski B, Paul C, Bryant J, West R, Siahpush M, D'Este C, Oldmeadow C, Palazzi K. Factors associated with concurrent tobacco smoking and heavy alcohol consumption within a socioeconomically disadvantaged Australian sample. Subst Use Misuse. 2016;51(4):459-70.

7. Brown LM: Epidemiology of alcohol-associated cancers. In: Alcohol, Tobacco and Cancer. edn. Edited by Cho C, Purohit V: Karger Publishers; 2006: 13-28.

8. Zhang Y, Wang R, Miao L, Zhu L, Jiang H, Yuan H. Different levels in alcohol and tobacco consumption in head and neck cancer patients from 1957 to 2013. PloS One. 2015;10(4):e0124045.

9. Meng C-L, Schmidt P. On the cost of partial observability in the bivariate probit model. International Economic Review 1985:71-85.

10. Marra G. On p-values for semiparametric bivariate probit models. Statistical Methodology. 2013;10(1):23-8.

11. Alkan Ö, Abar H. Determination of factors influencing tobacco consumption in Turkey using categorical data analyses ${ }^{1}$. Archives of Environmental \& Occupational Health 2019:1-9.

12. Falk D, Hsiao-Ye Y, Hiller-Sturmhöfel S. An epidemiologic analysis of co-occurring alcohol and tobacco use and disorders. Alcohol Research. 2006;29(3):162.

13. Manrique J, Jensen $\mathrm{HH}$. Consumption of tobacco and alcoholic beverages among Spanish consumers. Southwestern Economic Review. 2004;31(1):41. 
14. Medina-Solís C, Pontigo-Loyola A, Pérez-Campos E, Hernández-Cruz P, Ávila-Burgos L, MendozaRodríguez M, Maupomé G. National survey of oral/dental conditions related to tobacco and alcohol use in Mexican adults. International Journal of Environmental Research Public Health. 2014;11(3):3169-84.

15. Anand A, Roy N. Prevalence and determinants of co-use of alcohol and tobacco among men in working age group (18-59 years) in India. Epidemiology, Biostatistics and Public Health 2016, 13(1).

16. Phaswana-Mafuya N, Peltzer K, Pengpid S. Concurrent tobacco use and risky drinking in South Africa: results from the South African National Health and Nutrition Examination Survey. Journal of Psychology in Africa. 2018;28(4):316-22.

17. Das D, Maity N, Singh H. A study of pattern of alcohol and nicotine dependence: an observational study. Minerva Psichiatr. 2018;59(1):16-21.

18. Liao Y, Chen X, Tang J. Differences of cigarette smoking and alcohol consumption by sex and region in China: a population-based, multi-stage, cluster sampling survey. The Lancet. 2017;390:54.

19. Neufeld KJ, Peters D, Rani M, Bonu S, Brooner R. Regular use of alcohol and tobacco in India and its association with age, gender, and poverty. Drug Alcohol Depend. 2005;77(3):283-91.

20. Cui Y, Zhu Q, Lou C, Gao E, Cheng Y, Zabin LS, Emerson MR. Gender differences in cigarette smoking and alcohol drinking among adolescents and young adults in Hanoi, Shanghai, and Taipei. J Int Med Res. 2018;46(12):5257-68.

21. He Z, Bishwajit G, Yaya S. Prevalence of Alcohol and Tobacco Use among Men and Women in Namibia. International Journal of Environmental Research Public Health. 2019;16(1):59.

22. Intarut N, Pukdeesamai P. Socioeconomic inequality in concurrent tobacco and alcohol consumption. Asian Pacific Journal of Cancer Prevention: APJCP. 2017;18(7):1913.

23. Pengpid S, Peltzer K, Puckpinyo A, Thammaaphiphol K. Conjoint moderate or high-risk alcohol and tobacco use among male out-patients in Thailand. South African Journal of Psychiatry 2016, 22(1).

24. De Silva V, Samarasinghe D, Hanwella R. Association between concurrent alcohol and tobacco use and poverty. Drug Alcohol Rev. 2011;30(1):69-73.

25. Hamplová D: Marital Status, Smoking and Binge Drinking in Comparative Perspective. SociológiaSlovak Sociological Review 2018, 50(6):647-671. 